ESCENA

Revista de las artes
Publicación semestral. ISSN 1409-2522

Volumen 77 - Número 2

Enero - Junio 2018

\title{
Manifestaciones de masculinidad en el baile tradicional guanacasteco: estudio de caso Taller de Danza Folclórica Nahualt
}

Masculinity manisfestations in the traditional Guanacastecan dance: Taller de Danza Folclórica Nahualt case study

Yorleny Espinoza Jiménez

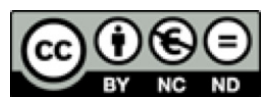

Esta obra está bajo una licencia Creative Commons Reconocimiento-No comercial-Sin Obra Derivada 


\title{
Manifestaciones de masculinidad en el baile tradicional guanacasteco: estudio de caso Taller de Danza Folclórica Nahualt
}

\author{
Masculinity manisfestations in the traditional Guanacastecan \\ dance: case study Taller de Danza Folclórica Nahualt
}

\author{
Yorleny Espinoza Jiménez ${ }^{1}$ \\ Universidad Nacional de Costa Rica \\ Guanacaste, Costa Rica
}

Recibido: 21 de setiembre de 2017 Aprobado: 12 de octubre de 2017

\begin{abstract}
Resumen
Este estudio tiene como objetivo analizar las manifestaciones subjetivas de la masculinidad desde los gestos, instrumentos y formas de cortejo puestos en práctica en tres espectáculos del Taller de Danza Folclórica Nahualt; La chola y el sabanero, El dulce hacer y Chalanadas. Además, busca demostrar que el espacio del baile tradicional en Guanacaste es un momento de construcción cultural y de generación de conocimiento el cual debe estar siempre abierto y sujeto a una transformación oportuna.
\end{abstract}

Palabras clave: masculinidad; gestos; artefactos; cortejo; identidad

\begin{abstract}
This study has as its main objective to analyze the subjective manifestations of masculinity from the gestures, instruments and courtship ways put into practice in three different shows by the Taller de Danza Folclórica Nahualt; La chola y el sabanero, El dulce hacer and Chalanadas. Also, this work intends to demonstrate that the space for the traditional dance in Guanacaste is a moment of cultural construction and generation of knowledge that must be always opened and subject to a timely transformation.
\end{abstract}

Keywords: masculinity; artifacts; gestures; courtship; identity

1 Máster en Segundas Lenguas y Culturas con énfasis en Inglés como Lengua Extranjera por la Universidad Nacional de Costa Rica (UNA). Doctoranda en Estudios de la Sociedad y la Cultura en la Universidad de Costa Rica. Profesora de inglés en la UNA, Sede Región Chorotega, Campus Nicoya. Correo electrónico: yorleny.espinoza.jimenez@una.cr 


\section{Introducción}

Existe, en Costa Rica, propiamente en la provincia de Guanacaste, una identidad cultural definida por su riqueza en tradiciones expresadas en las diversas manifestaciones artísticas y consolidada, debido al interés que han tenido sus habitantes en mantenerla viva y compartirla con el resto del país y el mundo. Cuando se menciona la palabra Guanacaste, aspectos clásicos y únicos de las costumbres de esta provincia inundan la memoria de las personas que conocen y saben que este es un lugar culturalmente variado en expresiones culturales como la gastronomía, la música, la poesía, las leyendas, entre otros aspectos. En el artículo La guanacastequidad, Floria Díaz Rível (1997) apunta:

El guanacasteco es diferente a todos los habitantes del país por su carácter multirracial, por su devenir histórico, sus muchas peculiaridades en su conformación socioeconómi$\mathrm{ca}$, en el lenguaje, en muchos bailes particulares, en el uso de marimba como instrumento musical, en el arte culinario, en sus canciones y música (p. 13).

Por ende, el guanacasteco tiene ciertas características muy singulares que distinguen su forma de vida. El cantautor y folclorólogo nicoyano Abdenago Torres Meléndez, mejor conocido como Nago de Nicoya, recientemente, distinguido con el máximo reconocimiento en el campo del folclore que otorga el Consejo Internacional de Organizaciones de Festivales de Folclore y de las Artes Tradicionales (CIOFF), asociación que forma parte de la UNESCO, ofrece una explicación muy gráfica sobre los aspectos relacionados con esas particularidades desde la perspectiva histórica y política, reflexiona en lo siguiente:

la interacción que se dio entre los indígenas de diferentes grupos desde México, Nicaragua y Panamá permitió la mezcla de culturas; por ejemplo, la variedad de grupos indígenas presentes en la zona; los Otomíes, los Nahualtes, los Nicaraos, los Chorotegas, es lo que le da a Guanacaste esa diversidad cultural tan rica en lenguas diferentes y afinidades ... el gobierno establecido en la zona de Nicoya fue, específicamente, con un cacique, con sus comidas, con su música, sus bailes, con sus monedas, su vestuario².

Una forma de ilustrar esas peculiaridades es la presencia de manifestaciones culturales propias y distintivas de la cultura guanacasteca, como lo es el baile tradicional guanacasteco. Este es una de las expresiones artísticas más antiguas y es descrita como una de las formas más completas de expresión. El baile es un fenómeno que, por su trascendencia, describe y explica la construcción social y cultural de la vida cotidiana de un pueblo a través de los movimientos del cuerpo humano. En términos generales, la danza o baile es una actividad física esencial debido a la inmersión social

2 Entrevista realizada a Abdenago Torres Meléndez por Yorleny Espinoza Jiménez el 22 de mayo, 2016, en Sámara, Nicoya, Guanacaste. 
que esta conlleva como hecho social, histórico, económico, político, ideológico y cultural. Sobre lo anterior, Katz (2004) explica:

La expresión corporal es el encuentro de la persona con su propio cuerpo, utilizando múltiples recursos a su alcance para lograr una mayor conciencia de él. Se basa en el movimiento visible o interior, en el gesto, en la actitud, nacidos de sensaciones, sentimientos e ideas, colectivas o individuales. Está apoyada en estímulos sonoros o en el silencio que facilitan la comunicación y la creatividad humanas. Es una actividad artística, educativa, grupal y metodológica. Es artística en la medida que, preservando el gesto auténtico -patrimonio expresivo del ser humano- propicia el desarrollo de un lenguaje creativo (p. 2).

Es decir, a través del baile, la persona desarrolla la capacidad de la actividad motriz y construye su esquema corporal. De esa forma, esta va conociendo su cuerpo y lo utiliza como vehículo de expresión, experimenta la realidad temporal y del espacio que ha de compartir con los demás en armonía y así, por medio del baile, la relación movimiento, corporalidad y sensibilidad se crean y se fortalecen. Sobre el baile tradicional guanacasteco, López (2012) hace hincapié en el objetivo primordial de lo que ella denomina el baile folclórico y menciona:

al centrarnos en el folklore infantil nos damos cuenta que lo aspectos predominantes en él son los juegos y las canciones, de ahí que este trabajo se base mayoritariamente en estos elementos. Mediante estos los niños van a intercambiar informaciones y experiencias, que van a servir para ampliar su visión sobre el entorno que les rodea (p. 12).

La práctica del baile es una práctica muy particular, pues permite crear un clima psicológico óptimo para llevar a cabo todo lo que el baile incorpora: movimientos corporales, sentimientos y emociones, lo que beneficia a los infantes durante su proceso de adquisición de otros conocimientos y de otras competencias para la vida. Sin embargo, la práctica del baile tradicional incorpora propiamente elementos culturales que hacen que el baile tome un matiz diferente y se convierta en un espacio de construcción de conocimiento. Al tener claro la relevancia del baile como expresión cultural en las personas, vale la pena ir más allá de lo que conlleva el disfrute del baile como forma entretenimiento, para analizarlo más a fondo. De ahí surge la idea de este estudio de caso, cuyo objetivo es analizar las manifestaciones subjetivas de la masculinidad desde los gestos, instrumentos y formas de cortejo, en los espectáculos de la Taller de Danza Folclórica Nahualt.

\section{Metodología}

Para iniciar este análisis se toman como objeto de estudio los miembros del Taller de Danza Folclórica Nahualt, dirigido por el coreógrafo Carlos Acuña Zúñiga. Dicho grupo es del cantón de Santa Cruz, provincia de Guanacaste, Costa Rica y tiene como objetivo general fomentar espacios de divulgación y proyección de la danza tradicional 
guanacasteca por medio de bailes ejecutados por los niños de la zona, que permitan consolidar la subjetividad del guanacasteco.

Esta investigación está centrada en el enfoque cualitativo y descriptivo, ya que se hace una recolección de datos, análisis y generación de resultados a partir de los espectáculos denominados La chola y el sabanero, El dulce hacer y Chalanadas, los que se pretenden analizar desde la subjetividad masculina en el baile y el rol de los participantes. Desde este enfoque, se identifica el fenómeno de estudio, se establecen relaciones entre tres conceptos específicos: los gestos, los instrumentos y el cortejo. Se identifican los aspectos por medio de observaciones no participantes y, de ahí se describen los mismos. Se lleva a cabo una recopilación de datos, se analizan con el fin de definir, finalmente, las distintas maneras en las que la masculinidad se manifiesta en los números artísticos del Taller de Danza Folclórica Nahualt. El estudio se realiza desde el análisis de los gestos de masculinidad que hacen los bailarines, los instrumentos que utilizan en sus espectáculos y las formas de cortejo que se muestran mientras ejecutan los bailes.

Los sujetos de estudios seleccionados por la investigadora son niños y jóvenes integrantes del Taller de Danza Folclórica Nahualt de Santa Cruz, Guanacaste entre los 2 años y los 20 años. En esta investigación se hace uso de la técnica de la observación (no participativa). Se analizan situaciones específicas, formalmente dirigidas y reguladas por un protocolo de indagación definido por la investigadora con los aspectos a estudiar, los cuales se encuentran incluidos en un formato específico. Este protocolo consiste en una guía que focaliza la mirada de la encargada del estudio, sin perder de vista el objetivo particular de la observación que se realiza, así como las preguntas a las cuales se busca dar respuesta, ya definidas bajo los tres grandes apartados; los gestos, los artefactos y las formas de cortejo. El análisis es meramente descriptivo e interpretativo, por lo que las notas, fotos y videos que se toman serán oportunamente utilizados en su totalidad para las interpretaciones de lo observado.

El estudio se realiza desde dos direcciones. Primero, se analizan fundamentos teóricos y además se incorporan las reacciones interpretativas que parten del análisis de los los tres aspectos observados mencionados, pero en tres momentos distintos, es decir, en tres números artísticos distintos. Cada número artístico tiene un contenido y un nombre diferente; el primero se llama La chola y el sabanero, el segundo El dulce hacer y el tercero Chalanadas. Cada espectáculo dura de una hora a dos horas. En todos los momentos, se utilizarán el registro por medio de fotografías, videos y audio, con el fin de graficar y describir escenas particulares de cada situación.

Las observaciones no participativas que se realizan, no tienen un orden específico para efectos de este trabajo, pues corresponden a tres diferentes puestas en escena que 
se estudiarán en la pertinencia que esta investigación lo amerite. Cada una de las presentaciones toma lugar en un sitio previamente informado por el instructor del grupo y en un tiempo determinado. Cada puesta en escena se analiza desde el mismo objetivo, planteado anteriormente, por medio de un instrumento de elaboración propia que permitió recolectar la información necesaria para el análisis, bajo los objetivos planteados.

\section{La masculinidad: pasado y presente}

Los bailes tradicionales guanacastecos se convierten en una forma de expresar temas cotidianos por medio del lenguaje gestual, el cual narra la cotidianidad de los pobladores en historias representadas. Estos bailes tradicionales ilustran, con ejemplos claros, desde su simbología y elementos, la presencia de masculinidad. Sobre este tema, propiamente, es pertinente citar algunas fuentes que faciliten el curso de este ensayo. Es necesario entender un poco más sobre la historia y el impacto que causa en el presente el poder de la masculinidad. Desde el periodo de la conquista y la colonización, la opresión ha formado parte del imaginario colectivo de los pobladores. Ha sido constante la disputa entre el dominador (europeo/español) y el dominado (indio, negro u otro esclavo). Sobre esto Aníbal Quijano (1999) expresa:

Esa distribución de identidades sociales sería, en adelante, el fundamento de toda clasificación social de la población en América. Con él y sobre él se irían articulando, de manera cambiante según las necesidades del poder en cada período, las diversas formas de explotación y de control del trabajo y las relaciones de género ( $p$. 140).

Debido a la dependencia histórico-estructural entre las tierras conquistadas y el dominio europeo, la opresión perpetuada contra los indígenas que habitaban estas tierras, especialmente a aquellas minorías como niños y mujeres, pasó a formar parte del imaginario y visión normal del mundo de los pueblos, de cómo debían ser sus vidas y su interacción con los demás miembros de su grupo social. El poder que ejercía el hombre hacia la mujer en la época de la conquista era evidente y, puede decirse que, aún quedan vestigios de esos comportamientos, los cuales son visibles en los bailes tradicionales guanacastecos, cuando se hace uso de ciertos artefactos que sugieren ser utilizados solo por hombres y se relacionan con la fuerza masculina.

Si bien, este trabajo no es sobre el impacto negativo de las manifestaciones subjetivas de la masculinidad en el baile tradicional guanacasteco, no hay duda de que las distintas formas de comportamiento machista, expresadas en el baile se han ido construyendo por muchos años a partir de los imaginarios de los pobladores de esta región, lo que ha calado, fuertemente, en el diario vivir de los que aún convivimos en esta época. El imaginario colectivo-cultural en los pueblos de América Latina se ha fundado desde la época de la 
conquista. Analizar las conductas desde el imaginario colectivo, por ejemplo, puede ser una de las posibles respuestas al por qué la masculinidad se expone en los bailes tradicionales. Uno de los pensadores más representativos en esta área es Gilbert Durand. En su obra Lo imaginario (2000), Durand explica el impacto del imaginario en el devenir de los seres humanos y asevera que:

Lo imaginario es, entonces, una categoría antropológica primordial y sintética; gracias a él es posible comprender las producciones artísticas de una sociedad y las representaciones racionales que la constituyen, así como el conjunto de la cultura, ya que comprende las imágenes producidas o por producir, las imágenes pasadas y las posibles imágenes (p. 18).

Si se toma lo anterior como referencia, se puede decir que, los bailes tradicionales guanacastecos tienen el mensaje de masculinidad transversalizado. Gracias a ese imaginario construido con base en el carácter histórico de la producción social, política y valores gestados, y la visión de lo heredado que se estructura en la puesta en escena o acto cultural. Sobre este punto, es acertado mencionar que la presencia de ese poderío y rasgos de masculinidad están muy presentes en el hombre guanacasteco. "Nago", de Nicoya, apunta que, dentro de esas características propias del guanacasteco, que podrían estar, en cierta manera, ligadas a la masculinidad, están su comportamiento y carácter. Él indica que el comportamiento de los guanacastecos es fuerte por razones lógicas y acota:

en Guanacaste se tiene que trabajar con animales en las grandes fincas de ahí que el carácter enérgico tiene relación con el trabajo duro, tiene que usar un vocabulario fuerte, aún para referirse a las mujeres, a amigos ... por eso algunas veces otros ven a los Guanacastecos como bruscos y groseros, aunque también luchadores, incluso dice que la fuerza del guanacasteco se marca también en la manera en la que ejecuta los instrumentos musicales (Torres, comunicación personal, 22 de mayo de 2016).

Lo anterior, muestra cómo las distintas formas de comportamiento machista que se han ido construyendo, tanto en los imaginarios individuales, como en los colectivos, van calando fuertemente en la cotidianidad de aquellos que vivimos en esta época. Además, las formas de difusión como el baile tradicional guanacasteco enfatizan esas conductas, lo que deja al descubierto el ejercicio de esta masculinidad en el escenario. Aunque estos aspectos históricos coyunturales sobre el proceso de descubrimiento y conquista influyeron en las expresiones de la región guanacasteca tales como la música, la danza, el arte, los diseños, los signos, los símbolos, las interpretaciones, las ceremonias, las formas arquitectónicas, los objetos de artesanía, así como las narraciones y otras expresiones artísticas o culturales, también han permitido que las manifestaciones se diversifiquen, se fusionen y se consoliden en la región. 


\section{Formas simbólicas en acción}

Para efectos de este estudio, las formas simbólicas son analizadas como un producto meramente estructural, según lo que describe Alfred Schütz (1993), de quien imagina las acciones como la simulación y reparación. Afirma que la comprensión observacional de la conducta exterior de la otra persona no basta para contestar las preguntas que otros tengan. Él apunta que esas son cuestiones de significado subjetivo que no pueden contestarse simplemente observando la conducta de alguien por su estructura. Además, menciona que, aunque primero observamos la conducta corporal, para comprenderla luego la ubicamos en un contexto más amplio de significado (p. 57). Clifford Geertz (1973) es uno de esos teóricos que quiso, en su momento, dejar de lado las relaciones sociales estructuradas, pero en determinado momento se interesó más en lo que él llamó la concepción estructural y la definió como:

Cualesquiera que sean las otras diferencias que presenten los llamados símbolos o sistemas de símbolos cognitivos y los llamados expresivos, tienen por lo menos algo en común: son fuentes extrínsecas de información en virtud de las cuales puede estructurarse la vida humana, son mecanismos extrapersonales para percibir, comprender, juzgar y manipular el mundo. Los esquemas culturales - religiosos, filosóficos, estéticos, científicos, ideológicos - son 'programas'; suministran un patrón o modelo para organizar procesos sociales y psicológicos, así como los sistemas genéticos proveen un correspondiente modelo de la organización de procesos orgánicos (p. 189).

Lo que sugiere Geertz es analizar las formas simbólicas en relación con los contextos sociales estructurados, con el fin de darle un nuevo norte a los estudios sobre contextos simbólicos. Geertz, además, propone el estudio de los símbolos como comunicación de masas con el uso de la tecnología tanto para producir, como para transmitir formas simbólicas y otras expresiones de distinto tipo. Todo con el objetivo de influenciar procesos mercantilistas y de transmisión global (1973, p.187), asunto que, de ninguna manera, es parte de esta investigación. Por su parte, John B. Thompson (1993) expone su propia idea acerca de las formas simbólicas, en la manera en la que él decide replantearlo y las describe como:

El estudio de las formas simbólicas - es decir, las acciones, los objetos y las expresiones significativos de diversos tipos - en relación con, contextos y, procesos históricamente específicos y estructurados socialmente, en los cuales, y por medio de los cuales, se producen, transmiten y reciben tales formas simbólicas ( $p$. 203).

La descripción anterior permite entonces, analizar la información recopilada de las observaciones, identificar los aspectos e interpretarlos desde las formas simbólicas; gestos, artefactos y formas de cortejo más relevantes presentes en el baile tradicional guanacasteco. En el libro La sociología del cuerpo, Le Breton (2002) menciona tres momentos 
importantes en el estudio de la corporeidad humana que pueden ser analizados desde las observaciones. El primer ángulo de análisis puede ser la condición de actor en sus diferentes componentes. Como segundo punto, la observación desde los elementos de análisis del cuerpo, pero no la unión entre ellos, sino, por medio de la sociología del cuerpo, es decir, las lógicas sociales y culturales. Dichas formas de observación coinciden, considerablemente, con los aspectos estudiados e identificables en las puestas en escena del Taller de Danza Folclórica Nahualt: los gestos, los artefactos y las formas de cortejo.

\section{Los gestos}

Si hablamos de los gestos como símbolos se puede decir que, el modo de existencia primaria de las alegorías parte, inicialmente, de la idea de que los símbolos son medios de comunicación aprendidos, transmitidos y heredados. Al respecto, Norbert Elias (1994) en su libro Teoría del símbolo menciona que todos los símbolos son formas de comunicación que tienen una significancia y van dirigidos de un grupo a otro, dichos mensajes son interpretados individualmente o intersubjetivamente (p. 36). Por esta razón, el significado o interpretación de símbolos o gestos es, particularmente, comprendido por los que pertenecen a ese grupo. Sin embargo, Butler en su libro Deshacer el género (2004), apunta que el cuerpo responde, no solamente a lo que se desea en individualidad, sino también al deseo en colectivo. En este punto, la influencia de la perspectiva masculina denota dominio en el cuerpo femenino, tal y como se evidencia en el baile tradicional guanacasteco. Sobre la corporalidad Butler (2004) apunta:

¿Y qué ocurre con el cuerpo? Este es el referente del acto; son sus actividades sobre las que se informa, las que se refieren, las que se comunican. Pero en la confesión el cuerpo actúa de nuevo, muestra su capacidad para realizar un acto y anuncia, aparte de lo que realmente se dice, que está allí sexualmente de una forma activa (p. 235).

Si se parte de este enunciado, se puede decir que el baile tradicional guanacasteco es un baile cargado de gestos que comunican, pero, a la vez, confiesan. En muchos de esos gestos la masculinidad está implícita y explícita al mismo tiempo, ya que, al ser expuestos, su objetivo fundamental es transmitir un mensaje, y al ser interpretados lo intrínseco sale a relucir. Por ejemplo, en La chola y el sabanero, en El dulce hacer y en Chalanadas, los hombres deben mover sus brazos de forma fuerte, de modo que, demuestren la forma en que los sabaneros y campesinos trabajaban en el campo. El uso adecuado de los brazos definiría la hombría de cada individuo y del grupo como tal. También, ellos zapatean con energía hacia el suelo, sus botas suenan fuerte y rasgando el suelo con la parte interior del pie; levantan sus pies y doblan sus rodillas con firmeza. La intención de este particular movimiento en el baile es demostrar la fuerza física del hombre al trabajar la tierra en comparación con otros hombres. Además, el zapateado fuerte y ruidoso simboliza la hombría; rasgo peculiar 
con el deben conquistar a las mujeres. Por otro lado, el zapateado denota confrontación hacia otros hombres; el zapateado junto a un buen grito incita a la pelea para determinar el dominio del territorio. Tal y como sucede en Chalanadas, en donde un hombre trata de conquistar a una mujer con la demostración de su fuerza física en distintos momentos, pero que culmina con una pelea contra otro hombre por el amor de la dama.

Si bien la mujer en el baile tradicional guanacasteco también zapatea, no lo hace con tanta energía como el hombre, pues es más sutil y ligero. Además, el movimiento de los pies en los hombres, junto con ese zapateo particular, muestra la seguridad que todo hombre debe tener en su diario vivir, de ahí que sea evidente la masculinidad en el baile con un gesto tan normal como la movilidad de brazos y pies. Sin embargo, la posición de las manos en el hombre, mientras ejecuta el baile tradicional guanacasteco, es fundamental, deben colocarse por detrás de la cintura, pues eso denota fortaleza, además de elegancia y decoro, sus hombros erguidos sugieren prestancia. El movimiento de manos y hombros al tomar las herramientas de trabajo y pretender estar arando la tierra, intenta dejar claro que el trabajo del campo es duro y que solo ellos lo saben hacer.

Otro ejemplo de masculinidad en el uso de lenguaje gestual, está en la coreografía "el vaquetero", que forma parte del espectáculo La chola y el sabanero, pues los hombres se toman fuertemente sus genitales para hacer alusión de su lado viril. Se considera que, quienes ejecutan las labores más duras en la finca son los vaqueteros, los montadores y los lazadores. Por tanto, sus funciones son mayormente relacionadas con la hombría y la virilidad, debido a la fuerza física que ellos deben tener al montar o trabajar con el ganado, lo cual es visto como un gran atributo por las mujeres.

\section{Los artefactos}

Los artefactos $u$ objetos utilizados en el baile tradicional guanacasteco tienen una razón de ser, una explicación y su respectiva significancia; son aspectos que van más allá del elemento en sí. Hernando (2012) explica que, algunos objetos iguales pueden ser analizados desde otros conceptos o lógica, debido a que los contextos socioculturales son cambiantes y manipulados por los sujetos en sociedad. Sobre esta nueva visión, él apunta:

Sin embargo, posiciones más recientes comienzan a demostrar la imposibilidad de separar sujetos y objetos en el análisis de una cultura: si los objetos de distintas culturas son diferentes es porque las personas que los fabrican también lo son. Desde este punto de vista, resulta obvio que las personas construyen la cultura material tanto como la cultura material construye a las personas. Es decir, somos como somos porque utilizamos determinados objetos, y porque somos así, fabricamos unos objetos y no otros (p. 19). 
Por tanto, la utilización de artefactos en el baile tradicional guanacasteco deja en evidencia que, dichos elementos contribuyen en esa construcción material de la cultura como base para definir la identidad. En este estudio de caso, el baile tradicional ejecutado por los miembros del Taller de Danza Folclórica Nahualt muestra, claramente, la subjetividad masculina a través de los objetos que forman parte de los cuadros artísticos.

Un ejemplo de lo anterior se presenta en el acto artístico La chola y el sabanero, se hace un uso reiterado de los elementos vaqueta y machete. En esta puesta en escena, esos artefactos simbolizan el trabajo en el campo, pues son interpretadas con el fin de que los espectadores identifiquen estos artefactos como símbolos del trabajo duro y la fuerza del hombre que, en conjunto, definen su masculinidad. El público tiene una reacción de asombro pues dichos instrumentos son utilizados con fuerza y mucha coordinación, lo que causa un efecto de admiración. Mientras tanto, el rol de las mujeres es bailar con unas bateas para simular ser cocineras. Ellas mueven sus enaguas con sensualidad y una sonrisa constante. Lo mismo sucede en El dulce hacer, donde las mujeres tienen su papel fundamental en la cocina alistando la comida para los peones. Por otro lado, en Chalanadas el papel fundamental de la mujer es estar sentada, lista, finamente vestida, muy arreglada para recibir halagos por parte del hombre enamorado.

\section{El cortejo}

Es relevante la relación entre la sexualidad humana y el lenguaje; sea este oral o gestual, ya que por medio del lenguaje las personas dan significado a sus comportamientos. A través de sus actuaciones o conductas, las personas pueden expresar sentimientos y emociones. Ante esto, Arias (1994) expresa "al ser un instrumento de comportamiento social, el lenguaje dentro de la educación sexual juega un papel importante en la socialización de los individuos" (p. 46). El cortejo es una de las formas más antiguas de relación entre los seres humanos, por ende, resulta interesante analizarlo desde el baile tradicional guanacasteco.

Es evidente que, en el baile tradicional guanacasteco, los roles de género están bien definidos y las ejecuciones propuestas por el Taller de Danza Folclórica Nahault son un ejemplo de ello. Sobre este tema en particular, es pertinente mencionar lo que teoriza Simone de Beauvoir en su libro El segundo sexo (1998) a partir de su frase célebre: "no se nace mujer, se llega a serlo" (p. 63), que ha sido la premisa para que muchos otros estudios consideren que el género va más allá del sexo. Ella explica que la relación mujeres y mundo se basa en los constructos socioculturales que ellas mismas se crean. Además, apunta que la comprensión de su feminidad depende de su propia autoconciencia, determinada por lo sociocultural.

Beauvoir (1998) propone que el género es un dato asignado a toda persona, desde el mismo momento del nacimiento, así como lo es el sexo. También sugiere que el ser mujer, 
o el ser hombre, no es cuestión de nacimiento, sino que, se relaciona con la socialización y la naturalización social de ciertas conductas. Entre esas formas de socialización se incluye el cortejo, el cual viene definido socialmente por los roles. Por un lado, el hombre conquistador y, por otro lado, la mujer conquistada. A este punto, surge la idea de que la mujer se define en relación al hombre, pues el arraigo a conductas patriarcales produce el efecto de no poder distinguir entre lo natural o lo cultural, previamente aprendido; lo que es equivalente a decir que el género es la división de los sexos impuesta por la sociedad. En el caso del baile tradicional guanacasteco, se puede hablar de elección directa de roles de género, de elección predeterminada por constructos socialmente aceptados. Así, los ejecutantes, hombres y mujeres, son conscientes de los roles de género que la puesta en escena requiere para demostrar la socialización que se desea. Mediante el baile se adoptan los roles de género, en tanto, las bailarinas y los bailarines se adentran en una progresiva interpretación y reinterpretación de las normas socioculturales.

En su libro El género en disputa (2007), Butler menciona que la orientación sexual, la identidad sexual y la expresión de género son el resultado de una construcción social, histórica y cultural. También se opone a la idea de que existan papeles sexuales o roles de género biológicamente delimitados por la naturaleza humana. Sin embargo, la ejecución del baile tradicional guanacasteco en estudio incluye el material con el cual se elabora la propia visión de los sujetos y, a la vez, se identifica la opresión que recibe la mujer como dependiente del hombre al someterse a ciertos comportamientos de la parte dominante masculina. Por ejemplo, estar bella y delicadamente vestida, estar lista para ser conquistada, hacer del ambiente de la cocina su espacio de desarrollo, estar dispuesta a recibir muestras de amor rudas, como sujetarla con un mecate, tal y como sucede en La chola y el sabanero cuando el hombre simula amarrarla y traerla hacia él, haciendo los mismos movimientos como si estuviera lazando a un animal.

Sobre el tema de género, Butler insiste en que no existe tal imposición, ella sugiere que existe una elección de unos rasgos social y culturalmente establecidos, por lo que acota que la voluntad de sometimiento es equivalente a la voluntad de rebeldía. Las puestas en escena en cuestión no proyectan esa rebeldía por parte de las mujeres. Por tanto, promueve la teoría de Butler sobre la performatividad, lo cual también se puede leer desde el papel que toman las mujeres en el baile, al ser cortejadas y en la repetición de rituales, dentro del mismo baile, que permiten identificar dos géneros culturales: el femenino y le masculino. El cortejo evidenciado en los bailes en cuestión se ve, profundamente, manipulado por el género, entendiéndose por este "el conjunto de aquellos valores y normas que normalizan a las mujeres y a los hombres respecto a los modelos femenino/masculino en un sistema binario" (González, 2016, p. 5). Por lo tanto, los roles de género establecidos en las formas de cortejo identificadas en los bailes sugieren normas socialmente ya construidas, desde la feminidad o 
la masculinidad.

Con el fin de ilustrar las manifestaciones de subjetividad masculina en el baile tradicional guanacasteco por medio del cortejo, se interpretan los momentos claves en los distintos espectáculos. En primer lugar, en el espectáculo El dulce hacer, en el que se monta toda la escena en un trapiche, en cierto momento de la ejecución del baile, las mujeres son acorraladas por mecates y chuzos simulando la apropiación de ellas por parte de los hombres como sus dueños. En segundo lugar, en Chalanadas se muestra, claramente, como los hombres tratan de conquistar a sus mujeres. Ellos siempre fingen ser los acosadores, al andar siempre detrás de las mujeres, aunque ellas los desprecien y sean indiferentes. La historia termina cuando el hombre logra su cometido: conquistarla. A lo largo del baile, el hombre demuestra que tiene el poder y al final surge la conquista. Estas expresiones o representaciones de masculinidad, expuestas en los bailes estarían muy relacionadas con la violencia simbólica de la que habla Pierre Bourdieu (1998), quien apunta:

la violencia simbólica, violencia amortiguada, insensible, e invisible para sus propias víctimas, que se ejerce esencialmente a través de los caminos puramente simbólicos de la comunicación y del conocimiento o, más exactamente, del desconocimiento, del reconocimiento o, en último término, del sentimiento (pp. 11-12).

Podría determinarse, entonces, que las emociones bajo las cuales se compone, se transmite y se interpreta un baile merecen todo un estudio pues, sin lugar a duda, el alcance del sentimiento de los ejecutantes repercutirá en la forma en que los simbolismos se traducen a la realidad y que, en el ritual del cortejo tienen un papel fundamental.

\section{Contexto histórico en el espectáculo}

Desde mediados del siglo XX pensadores como Martín Heidegger, una de las principales figuras en los estudios contemporáneos, comienza a influir en la deconstrucción estructural, propuesta por el Existencialismo de la época. Este filósofo propone la destrucción de las estructuras metafísicas con el llamado giro lingüístico. Sobre lo anterior Heidegger sugiere lo siguiente:

Dejemos de una vez de representar lo técnico solo técnicamente, esto es, a partir del hombre y de sus máquinas. Prestemos atención a la llamada bajo cuyo influjo se encuentran en nuestra época, no solo el hombre, sino todo ente, naturaleza e historia en relación con su ser (s.f., p.10).

Se puede interpretar que Heidegger piensa que la verdad de todo ser es la esencia que lo define, de ahí que el rescate la importancia de ir a la naturaleza y a historia del ser, pues eso es lo que prevalece. Por su parte, en el libro Hacia una antropología de los mundos 
contemporáneos (1995), Marc Augé explica con claridad el papel de la contextualización histórica cuando se analizan las formas simbólicas en cualquier tipo de expresión cultural. Muy acertadamente, explica que la reflexión histórica colabora en la interpretación de los símbolos. Así, la historia del pasado y del presente se convierte en una guía o referencia fundamental. La dualidad que pueda presentarse por la relación de la Antropología y la Historia no es contraproducente. Más bien, interrogarse sobre el lugar que ocupa la conciencia histórica y la historicidad en los pueblos, actualmente, no solo debe hacerse desde la Antropología social o Etnología, sino que, la unión de la Antropología y la Historia enriquece, fuertemente, cualquier trabajo en Estudios culturales (pp. 14-15).

Sobre la relevancia histórica del espectáculo El dulce hacer, es necesario apuntar que en este se rescata un contexto socio-histórico importante en el desarrollo del país. El baile toma lugar en el trapiche y la zafra (corta de la caña de azúcar), estos espacios se convierten en elementos fundamentales en escena, debido a que ambos incitan a la inmersión histórica en la época de la colonia. Los trapiches, en ese periodo eran manejados por las propias familias y eran talleres de corte doméstico. El trapiche es un fenómeno cultural y económico de muchos países en América Latina y, en la actualidad, ha sufrido algunas transformaciones.

En relación con el contexto socio-histórico en el que se montan los espectáculos $\mathrm{La}$ chola y el sabanero y Chalanadas, se podría decir que, estos bailes se insertan en la época de la colonia en Costa Rica, la cual se caracterizó por ser un periodo de trabajo duro. En Guanacaste, por ejemplo, se trabajaba con animales en las grandes fincas, de ahí que el carácter enérgico del hombre guanacasteco que tiene cercana relación con el trabajo duro.

\section{Discusión final}

El análisis presentado en este ensayo sobre la presencia de subjetividad masculina en los gestos, los artefactos o instrumentos y las formas de cortejo utilizadas en el baile tradicional guanacasteco en tres distintos espectáculos del Taller de Danza Folclórica Nahualt: La chola y el sabanero, El dulce hacer y Chalanadas es muy variado y evidencia que sí hay manifestaciones de masculinidad en las ejecuciones antes mencionadas. El análisis incluye la perspectiva del estudio simbólico y el contexto histórico-cultural, lo cual permite validar la riqueza del espectáculo como tal. Sin embargo, se insiste en esos rasgos de subjetividad masculina por ser el tema de estudio, sin desprestigiar el baile tradicional guanacasteco como tal.

Es un hecho que el estudio de las formas simbólicas utilizadas por los niños y jóvenes en sus espectáculos incluye acciones, gestos, artefactos y maneras que permiten que esa simbología se traduzca comúnmente en el diario vivir. A partir de estas, se analizan ciertas costumbres, tradiciones, intercambios de sentimientos, de mensajes, entre otros aspectos que resultan esenciales y describen solo una parte, desgraciadamente, muy poco 
representativa, de lo que, culturalmente, representa la cotidianidad del ser guanacasteco. Es de suma trascendencia que la contextualización histórica de los espectáculos nunca quede desvinculada de la puesta en escena, pues eso es lo que enriquece el acto. Tanto los actores como los espectadores adquieren conocimiento y contribuyen a que la cultura no se disperse. Siempre deben existir espacios para disfrutar de este derroche de cultura, talento y creatividad.

\section{Referencias}

Augé, M. (1995). Hacia una antropología de los mundos contemporáneos. Barcelona: Gedisa.

Arias, A. M. (1994). La sexualidad humana y el lenguaje popular. Ciencias Sociales, 66(9), 45-54.

Beauvoir, S. (1998). El segundo sexo (vol. 1). Madrid: Cátedra.

Bourdieu, P. (1998). La dominación masculina. Paris: Éditions du Seuil.

Butler, J. (2007). Género en disputa. Barcelona: Paidós.

Butler, J. (2004). Deshacer el género. Barcelona: Paidós.

Butler, J. (2002). Cuerpos que importan: sobre los límites materiales y discursivos del «sexo». Buenos Aires: Paidós.

Díaz, F. (1997). La guanacastequidad. Revista de Ciencias Sociales de la Universidad de Costa Rica, $75,11-22$.

Durand, G. (2000). Lo imaginario. Barcelona: Ediciones de Bronce.

Elias, N., Kilminster, R., \& Álvarez Flórez, J. M. (1994). Teoría del símbolo: un ensayo de antropología cultural. Barcelona: Península.

Geertz, C. (1973). La interpretación de las culturas. Barcelona: Gedisa.

Heidegger, M. (s. f.). El principio de identidad. Recuperado de http://www.udec.cl/ alejanro/pepe/hei4.pdf

Hernando, A. (2012). La fantasía de la individualidad: sobre la construcción sociohistórica del sujeto moderno. Recuperado a de http://books.google.com/books?hl=en\&lr=\&id=FPsabga_GXQC\&

Le Breton, D. (2002). La sociología del cuerpo. Buenos Aires: Nueva visión.

Quijano, A. (1999). Colonialidad del poder, cultura y conocimiento en América Latina. Textos básicos. México: Fondo de Cultura Económica.

Schütz, A. (1993). La construcción significativa del mundo social. Barcelona: Paidós.

Della Ventura González, A. (2016). Género, identidad y performatividad en Judith Butler (libro digital). Recuperado de goo.gl/YtT8t4 